\title{
The value of postmortem experience in undergraduate medical education: current perspectives
}

This article was published in the following Dove Press journal:

Advances in Medical Education and Practice

II March 2015

Number of times this article has been viewed

\author{
Andrew R Bamber ${ }^{\prime}$ \\ Thelma A Quince ${ }^{2}$ \\ 'UCL Institute of Child Health, \\ London, UK; ${ }^{2}$ Department of Public \\ Health and Primary Care, Primary \\ Care Unit, School of Clinical Medicine, \\ University of Cambridge, School of \\ Clinical Medicine, Cambridge, UK
}

Correspondence: Andrew R Bamber UCL Institute of Child Health,

30 Guildford Street, London,

WCIN IEH, UK

Tel +4429207427I2

Email a.bamber@ucl.ac.uk

\begin{abstract}
The autopsy has traditionally been used as a tool in undergraduate medical education, but recent decades have seen a sharp decline in their use for teaching. This study reviewed the current status of the autopsy as a teaching tool by means of systematic review of the medical literature, and a questionnaire study involving UK medical schools. Teachers and students are in agreement that autopsy-based teaching has many potential benefits, including a deeper knowledge of basic clinical sciences, medical fallibility, end of life issues, audit and the "hidden curriculum". The reasons underlying the decline in teaching are complex, but include the decreasing autopsy rate, increasing demands on teachers' time, and confusion regarding the law in some jurisdictions. Maximal use of autopsies for teaching may be achieved by involvement of anatomical pathology technologists and trainee pathologists in teaching, the development of alternative teaching methods using the principles of the autopsy, and clarification of the law. Students gain most benefit from repeated attendance at autopsies, being taught by enthusiastic teachers, when they have been effectively prepared for the esthetic of dissection and the mortuary environment.
\end{abstract}

Keywords: medical education, autopsy, postmortem

\section{Introduction}

“Taceant colloquia. Effugiat risus. Hic locus est ubi mors gaudet succurrere vitae."

"Let conversation cease. Let laughter flee. This is the place where death delights to help the living."

The autopsy has a long history of use for physician education, indeed the word autopsy is derived from the ancient Greek "autos" (oneself) and "opsis" (sight); literally meaning "to see for oneself". ${ }^{1}$ The utility of the autopsy as a tool in both medical practice and medical education has remained well-recognized in more recent times. ${ }^{2-7}$ In light of this utility, the autopsy was in common and frequent use as a teaching tool throughout the early and middle parts of the last century, and regular attendance by medical students was expected.

Despite the high value placed on the autopsy as a teaching tool in the past, their use in this setting has dramatically declined, leading to a situation where many students will no longer see any autopsies at all during the course of the their undergraduate studies. ${ }^{8,9}$

The purpose of this review is to assess the literature, and canvass opinion and current practice in the UK. The aim was to understand the current value of the autopsy as a teaching tool in medical undergraduate curricula, and discuss areas of controversy, 
including the decline of the teaching autopsy. This review is limited to the subject of the autopsy in medical education; the use of embalmed donated cadavers in anatomy teaching will only be discussed in respect of contrasting features of the two techniques, highlighted in the literature and by respondents to the survey.

\section{Methods}

This review incorporates a thorough review of the medical literature, including structured queries in PubMed, and searches of appropriate society abstracts relevant to the subject of the autopsy in undergraduate medical education (eg, The Pathological Society of Great Britain and Ireland, The Association for Medical Education in Europe, and The Association for the Study of Medical Education). In addition, a short questionnaire consisting of 14 questions with free text response was sent to all medical schools in the UK with the objective of providing a snapshot of the current status of the autopsy in undergraduate medical education. The questionnaire also solicited the opinions of the individuals responsible for autopsy teaching concerning the utility of autopsy as a tool for medical teaching. The questionnaire is provided in the Supplementary material section.
As this questionnaire was sent only to faculty, enquired only about current practice, and was optional, research ethics approval was not required.

\section{Results}

The questionnaire was sent to each of the 33 undergraduate medical schools in the UK and responses were received from 20 (59\% response rate). The results of the questionnaire and the literature review are presented by topic below.

\section{The current status of autopsy in UK undergraduate medical education}

All but one of the participating schools allowed some students to attend autopsies during the course of their medical studies, although the format of this attendance varied (Table 1). All but three of the participating schools described some form of student-directed attendance, with students having to contact the mortuary or a tutor directly and arrange attendance. In some, opportunities for students to attend were encouraged by tutors during teaching sessions, or by the advertisement of pending autopsies and the use of a sign-up system. The degree to which students were actively encouraged appeared to vary. Even where attendance was encouraged, opportunities to

Table I Current use of autopsy for undergraduate teaching in 20 UK medical schools

\begin{tabular}{|c|c|c|c|c|c|c|}
\hline School & $\begin{array}{l}\text { Nature of } \\
\text { sessions }\end{array}$ & Coverage & $\begin{array}{l}\text { How arranged/who } \\
\text { instigates }\end{array}$ & Encouragement provided & $\begin{array}{l}\text { Format of } \\
\text { session* }\end{array}$ & $\begin{array}{l}\text { Average number of } \\
\text { sessions attended }\end{array}$ \\
\hline A & Compulsory & All & Routine part of the course & $\mathrm{N} / \mathrm{A}$ & {$[1]$} & $>2$ \\
\hline \multirow[t]{2}{*}{ B } & Compulsory & All & Routine part of the course & N/A & {$[1]$} & 1 \\
\hline & Formal SSC option & & Student & Highlighted in teaching sessions & & Several \\
\hline C & Compulsory & All & Routine part of course & N/A & {$[1]$} & 1 \\
\hline $\mathrm{D}$ & Requirement & $\begin{array}{l}\text { Graduate } \\
\text { entry only }\end{array}$ & $\begin{array}{l}\text { Routine part of course but } \\
\text { additional optional }\end{array}$ & Strongly encouraged & {$[1,2]$} & $\begin{array}{l}\text { I as requirement } \\
\text { Varies optional }\end{array}$ \\
\hline$E$ & Formal SSC option & All & Student & Highlighted in teaching sessions & {$[1,2]$} & Several/varies \\
\hline $\mathrm{F}$ & Formal SSC option & All & Student & Highlighted in teaching sessions & {$[1,2]$} & $2-3$ \\
\hline G & Formal SSC option & All & Student & None & {$[1,3]$} & 5 \\
\hline $\mathrm{H}$ & Formal SSC option & All & Student & Highlighted in teaching sessions & {$[1]$} & 2 \\
\hline I & Formal SSC option & All & Student & None & {$[1]$} & Several/varies \\
\hline J & Formal SSC option & All & Student & None & {$[1]$} & Several/varies \\
\hline K & Optional & All & Routine part of course & Highlighted in teaching sessions & {$[1]$} & Varies \\
\hline L & Optional & All & Routine part of course & Highlighted in teaching sessions & {$[\mathrm{I}]$} & Varies \\
\hline M & Optional & All & Routine part of course & Highlighted in teaching sessions & {$[1]$} & Varies \\
\hline $\mathrm{N}$ & Ad hoc/optional & All & Student & Highlighted in teaching sessions & {$[1]$} & I \\
\hline O & Ad hoc/optional & All & Student & Highlighted in teaching sessions & {$[1,3]$} & 3 \\
\hline$P$ & Ad hoc/optional & All & Student & Highlighted in teaching sessions & [2] & $\begin{array}{l}\text { 2-3 per term for } \\
\text { students who opt }\end{array}$ \\
\hline Q & Ad hoc/optional & All & Student & Sign up to postmortem sessions & {$[\mathrm{I}]$} & I \\
\hline $\mathrm{R}$ & Ad hoc/optional & All & Student & None & {$[1]$} & Varies \\
\hline S & Ad hoc/optional & All & Student & None & {$[1]$} & Varies \\
\hline $\mathrm{T}$ & Students do not atte & d postmorte & examinations & & & \\
\hline
\end{tabular}

Notes: *[1] Observation of whole autopsy; [2] Examination of individual organs; [3] Introduction to mortuary environment.

Abbreviations: SSC, student selected component; N/A, not applicable. 
experience postmortem examinations appeared dependent on specific circumstances such as being on placement and involved with a patient on whom a postmortem was being carried out, and the attitudes and opportunities provided by employers. In over half of the participating schools the initiative rested with students themselves.

Only three schools included obligatory attendance for all students on their undergraduate course, and in these schools integration into the curriculum was prominent. In one school it was integrated at two stages: early on through an introduction to postmortem and later as a component of an emergency medicine course. In another it formed part of training for death certification. In other schools where specific opportunities were provided for attendance, it was rare for this to be in the first year, but where attendance was student-directed, attendance could take place at any stage. In a further school, attendance was a course requirement but only for students on a graduate entry course and although a requirement, attendance was not enforced for students who objected.

In seven participating schools autopsy attendance was built into the curriculum by means of an optional student selected component or special study module. In a further four schools attendance of specific autopsy sessions were a routine part of the course.

In most schools where attendance was optional, it was not integrated into the general curriculum. There were exceptions; in one school, attendance was encouraged as an integral part of a course focusing on the duties of a doctor in relation to death. This also involved the role of the postmortem in providing an introduction to, and familiarization with, the role of the mortuary.

In schools where attendance was compulsory, teaching was formal and structured. This could take the form of reviewing case notes and formulating possible causes of death and questions for the postmortem, familiarization with issues of consent and the Human Tissue Authority's codes of practice and observing police interviews prior to attendance. Students attending compulsory autopsy teaching sessions generally attended both whole postmortem examinations and reconstruction. Structured outcomes included completion of mock death certificate, writing observed clinic-pathological correlations, and demonstrating understanding of how to approach bereaved relatives.

Most of the specifically directed student selected components offered were structured. In several cases preparation included prior appreciation of the esthetic and possible emotional impact of the mortuary and the postmortem examination process in addition to the legal and clinicpathological issues. Reflection, either in terms of group discussion and presentation or writing, figured in most as a learning outcome. Other learning outcomes mentioned included reflective writing following attending the inquest, completion of death certificates, and understanding the role of autopsy in clinical audits.

It was difficult for schools to provide details of the numbers of autopsies students see during their studies. Clearly in most participating schools attendance depended on students' personal level of interest. Compulsory attendance was generally limited to one or two cases. In general, attendance across all centers seemed to be in the region of single figures, but where student-directed opportunities existed students may have attended many more autopsies. However in the authors' experience this would be uncommon as, while technically possible, it would now be unusual for a student to attend many tens, or even hundreds, of autopsies. This is in stark contrast to medical training in the middle of the last century.

\section{Potential benefits of autopsy attendance (views of faculty)}

Views of pathologists and other medical teachers with regard to the autopsy have been discussed at length in the literature, predominantly by means of opinion papers by respected teachers and pathologists, ${ }^{4,10}$ and reviews of the published literature. ${ }^{11}$

A small number of more objective studies, ${ }^{9,12,13}$ have considered educators' views using questionnaires or interviews which tend to show similar results to those obtained in this study. The perceived educational benefits and problems have been grouped broadly in terms of impact on students' knowledge, skills, and attitudes.

\section{Impact on knowledge}

Most respondents cited benefits in terms of the impact on biomedical knowledge and knowledge about medico-legal issues surrounding death. Biomedical knowledge included positive impacts on the understanding of anatomy and pathology. The ability to see three-dimensional anatomy, in a freshly dead body (as opposed to an embalmed cadaver), was seen to be of particular use. Respondents highlighted the value of fostering understanding of anatomy and pathology in the context of the clinical history and an actual patient. This was thought to improve skills in clinico-pathological correlation. In addition to anatomy and pathology, other basic 
science uses were highlighted such as physiology, radiology, and clinical pharmacology.

In terms of medico-legal understanding, it was recognized that all doctors will come into contact with dead patients at some point in their careers and that attendance of autopsies provided an opportunity for them to consider the legal framework applying to the dead. Particular importance was placed on medical students developing awareness of issues of consent, and the role of the coroner or similar legal authority.

\section{Impact on skills}

Attending postmortem examinations was seen to have positive impacts on diagnostic and communication skills, potentially enhancing future patient care. Observing postmortems was seen by some as likely to foster broader differential diagnosis and the associated problem-solving methodologies for investigation. In addition to generating greater knowledge, postmortem attendance also enhanced students' abilities to describe more accurately what they observed.

Doctors fully aware of consent issues and who had attended postmortem examinations were seen as likely to be able to handle bereaved relatives in a more informed and understanding manner, both in terms of discussing the postmortem examination, and in discussing end of life issues.

\section{Impact on attitudes}

Several studies have highlighted the utility of the autopsy in the provision of the "hidden curriculum" in medical education; those aspects of medical practice which cannot be taught through formal teaching sessions, but are subconsciously absorbed by observation of teachers' and peers' attitudes and activities. , $^{9,10,12,13}$

Our respondents cited a wide range of attitudes, which attending postmortem examinations impacted on positively, including the ability to remain focused but distanced. Attending postmortems was also seen to enhance understanding of the role of the pathologist, and that of other health care professionals such as anatomical pathology technologists, and thereby also enhance understanding of inter-professional working. Attendance also helped foster appropriate attitudes toward death and the bereaved. It allowed students the opportunity to reflect on the limitations of modern medicine and come to terms with the fact that patients die. Furthermore, it helped students appreciate the impact of life style, social deprivation, and other socio-economic factors on health, well-being, and death.

Although respondents were generally positive regarding the educational benefits of attendance, a number of important caveats were mentioned: sessions had to be structured, teaching had to be active and the problem-solving process needed to be highlighted. While there was a feeling that students should not be over-protected from the realities of their profession and end of life issues, there needed to be awareness that some students may find autopsies emotionally and physically disturbing, and consequently students need to be adequately prepared and supported.

\section{Difficulties using autopsies}

Despite the many educational uses of the autopsy cited by our respondents, difficulties associated with utilizing autopsies for educational purposes and which have contributed to its decline in this respect were also highlighted.

Most significantly, the number of autopsies taking place has declined dramatically over the last 50 years. Autopsies can be performed in a variety of circumstances in the UK, some of which have traditionally been used more frequently to facilitate student teaching. Consented (hospital) autopsies are conducted at the request of either the family of the deceased or a clinician in cases where the cause of death is known and, although no examination is required by law, further useful information may be gained. Consented autopsies always require the consent of the family of the deceased. These examinations have traditionally formed the bulk of medical student teaching cases in the UK, as consent for research, education and training on the part of the family is explicit.

Medico-legal (coroner's) autopsies are conducted at the request of Her Majesty's Coroner (England and Wales) or the Procurator fiscal (Scotland) in cases where the cause of death is either unnatural or unclear. Coroner's autopsies require no consent from the family of the deceased, and there is no mechanism by which families can prevent a coroner's autopsy taking place. However, any part of a coroner's autopsy which does not bear upon the cause of death of the deceased, such as removal of tissue for research purposes, may only take place with the additional consent of the family.

A subset of coroner's autopsies take place where there is the suspicion of a criminal act (forensic or special autopsies), and such cases involve the police service and may utilize other professionals such as forensic scientists. Like all coroner's autopsies, forensic cases require no consent from the family of the deceased, and there is no mechanism by which families can prevent such an examination taking place. Any material may be retained from such autopsies as is deemed fit by the pathologist and the police under the authority of the Police and Criminal Evidence Act 1984, ${ }^{14}$ and no consent 
is required from the family for any part of the examination. As a result there are proportionally more forensic autopsies involving distressing injuries and circumstances, such as murder.

The lack of suitable consented autopsies for teaching was mentioned by several respondents. Since such autopsies traditionally formed the bulk of teaching cases, this has led inevitably to a decline in autopsy-based teaching. ${ }^{15-17}$ The reasons for the decline of the consented autopsy are complex, but involve a number of interconnecting issues. First, the organ retention scandals which came to public attention towards the end of the last century contributed to a strong negative public attitude towards the autopsy, and towards pathologists. ${ }^{18}$ Furthermore, the increasingly broad cultural mix of the UK population means that there are an increasing number of people with religious beliefs which either prohibit autopsy, or demand rapid burial.

Although these factors may have increased the likelihood of family members refusing consent for autopsy, their biggest impact is probably on the behavior of doctors themselves. Consented autopsies rely on doctors approaching members of the deceased's family and asking for their consent. Doctors are generally less inclined towards doing this in a climate which has evolved in the wake of organ retention scandals and increasing religious objections. ${ }^{15,19}$ Furthermore, as many doctors now entering practice will have never experienced attendance at an autopsy, it is likely that they will not feel adequately prepared to answer the family's questions and/or they may not realize the value of the autopsy, having never experienced autopsy-based teaching.

These issues could be addressed by improved training or positive action by pathologists, however the autopsy is forming an increasingly minor part of a histopathologist's workload. Indeed it is now possible for UK pathologists in training to give up autopsy pathology altogether, as autopsy pathology has become a standalone optional module in the histopathology curriculum. ${ }^{20}$ There has also been a significant increase in the workload of histopathologists, particularly in light of increasingly challenging targets for cancer turnaround times..$^{21,22}$ All of this reduces the time available to undertake autopsies, engage in teaching, encourage increased consented autopsy numbers, or provide alternative teaching methods. Several respondents to the questionnaire raised the issue of workload as a factor limiting the use of autopsies for teaching.

An alternative to the use of consented autopsies for teaching is the use of medico-legal autopsies. Indeed several respondents to the survey commented that most students attend these autopsies because of the demise of consented autopsies. There is evidence of such cases being used for teaching with some success. ${ }^{23,24}$ However there are a number of difficulties using these cases. Medical student attendance at coronial autopsies is permitted by law provided the coroner gives permission. ${ }^{25}$ Nevertheless, it is becoming clear that some coroners, are limiting students' attendance in order to "be on the safe side" and avoid possible family complaints. At least two respondents commented that it is not, or has not been, possible for students to attend medico-legal cases in their area because of blanket bans on attendance by the Coroner or Procurator fiscal, or because some mortuaries refuse entry to medical students on the misconceived grounds that it would be "contrary to the law". It should be noted that, whilst some centers reported difficulties using these types of autopsies for teaching, this is not a pattern seen throughout the UK. In other jurisdictions medical student attendance is more strictly controlled, for example New Zealand, where medical students are not permitted to attend medico-legal autopsies under any circumstances. ${ }^{6,26}$

Even where legal barriers to attendance at these types of cases do not exist, significant ethical questions are raised in respect of their use for teaching. Medico-legal autopsies take place without the consent of family members (in some cases expressly against the wishes of family members), hence the appropriateness of medical students' attendance without prior permission from the family is debatable. ${ }^{27,28}$ Even where it is decided that permission from the family should be sought, there is little agreement as to who should seek it. ${ }^{29-31}$

In addition to the decline in the number of consented autopsies, there has been a similar, albeit shallower, decline in medico-legal autopsies in the UK. Further, it is unclear how the number of medico-legal autopsies in the UK will be affected by the planned introduction of the medical examiners system. ${ }^{32}$

There are also practical concerns which make the use of autopsies for teaching challenging. Firstly, in recent years changes in the philosophy of medical education delivery have resulted in great time pressure on the curriculum in most medical schools. In particular there have been changes in the delivery and time allocation to specialties such as anatomy and pathology. ${ }^{11,33-39} \mathrm{~A}$ number of respondents commented on the lack of curriculum time for autopsy teaching, and that scheduling autopsy sessions was particularly difficult in view of the lack of advanced notice of available autopsies. The facilities for autopsies may also provide a technical challenge in terms of providing a health and safety compliant environment in which suitable numbers of students can be 
accommodated so as to not prevent their engagement with the procedure.

As interest has grown in the psychology of education, particularly with regard to teaching potentially distressing areas such as end of life care, concerns have been raised by both students and educators regarding the potential psychological harm which might be caused to students attending anatomic dissection or an autopsy. ${ }^{12,13,40-45}$ Such studies highlight several approaches which might reduce the negative psychological impact of autopsy teaching whilst retaining its utility. These include adequate preparation, discussion following the autopsy, and use of alternative teaching methods. The range of such alternative teaching methods in use in the UK is described below, but producing resources requires time, and requires at least one pathologist with a sufficient interest to lead and drive forward such an approach. Furthermore, one of the great benefits of autopsy teaching highlighted by both students and faculty was the role it played in preparing students for the reality of death in medical practice, ${ }^{24,46-48}$ Removing the direct nature of autopsy teaching might dilute this key advantage.

Some studies have suggested that adequate preparation prior to attending an autopsy would significantly reduce its emotional impact. ${ }^{24,45,47,49}$ A small number of respondents to the survey indicated that a phased introduction to the mortuary, perhaps involving images of the mortuary and a visit when not in use, was a routine part of medical student autopsy sessions.

Many of the problems facing autopsy based teaching involve a lack of time available on the part of pathologists however few schools mentioned the involvement of anatomical pathology technologists in teaching. Anatomical pathology technologists' ability and experience may vary but nevertheless, many have a wealth of experience which could be utilized in teaching, particularly in preparing students for the realities of the mortuary environment, and demonstrating basic three-dimensional anatomy.

Only one respondent mentioned the involvement of trainee pathologists in teaching: trainees undertook autopsies but it was frequently felt that it was "not appropriate" to add to their stress by increasing their "audience". This does not accord with the author's (ARB) experience, in that most trainees seem generally enthusiastic about demonstrating the whole autopsy, and/or their findings to medical students.

\section{Alternatives to direct attendance}

One approach to addressing the problems associated with attendance discussed above is to utilize the principles of autopsy practice in ways other than direct attendance. About half of the schools providing information reported using alternative approaches. Pathology specimens in some form (real, three-dimensional or virtual images) were used in casebased or problem-based learning. Videos of materials or in one case of the key steps of a real autopsy were also used. A small number of schools either had developed or were in the process of developing e-learning packages involving extensive use of postmortem material.

The use of such technologies has been described frequently in the literature, ${ }^{40-44,50}$ and the theoretical benefits are well established. However the use of such technologies and alternatives raises significant issues. First, finding time to create such resources and integrate them into the curriculum is extremely difficult. Second, many of the benefits of attending an autopsy relate to the "realness" of the situation, as opposed to for example the more artificial appearance of the organs and tissues in an embalmed anatomical cadaver. It is possible that, by moving autopsy experience away from the mortuary, part of this experience, and thus part of the benefit, would be lost.

Such methods are also subject to the same problems as direct attendance with regard to fitting them into an already packed undergraduate curriculum.

\section{Views of students}

Although the utility of autopsy in teaching medical students has been widely debated, few published studies have sought the opinions of medical students directly.

A summary of the features of the studies published in the literature considering medical student opinion on the autopsy is given in Table 2. The studies cover a wide variety of geographical areas where autopsy technique, quality, and case mix vary significantly. Students' involvement ranges from viewing of removed organs from natural deaths, to observing a complete autopsy where death was traumatic, to actually performing the autopsy themselves. The study group, study methodology and focus of the investigators also differs between studies. Their resulting heterogeneity makes statistical meta-analysis impossible.

Despite differences in studies, medical students have been found to express opinions, which can be divided into those related to cognition, society, and emotion to reflect Illeris' three dimensions of learning (Table 3). ${ }^{68,69}$

It is notable that many of the key responses of students are positive - most see autopsy attendance as useful in medical education, particularly with regard to learning basic sciences, integrating clinical medicine with pathology, and 


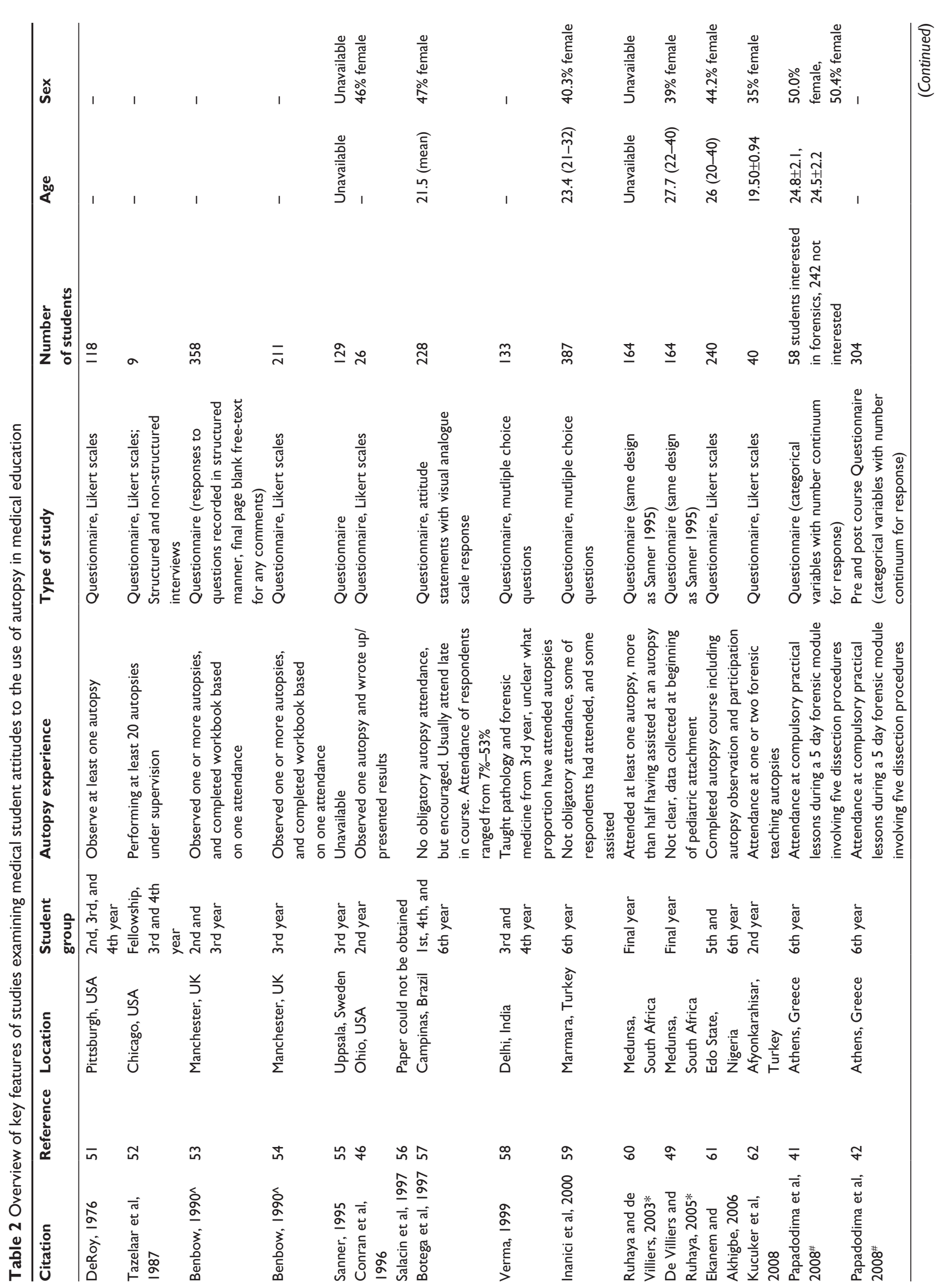




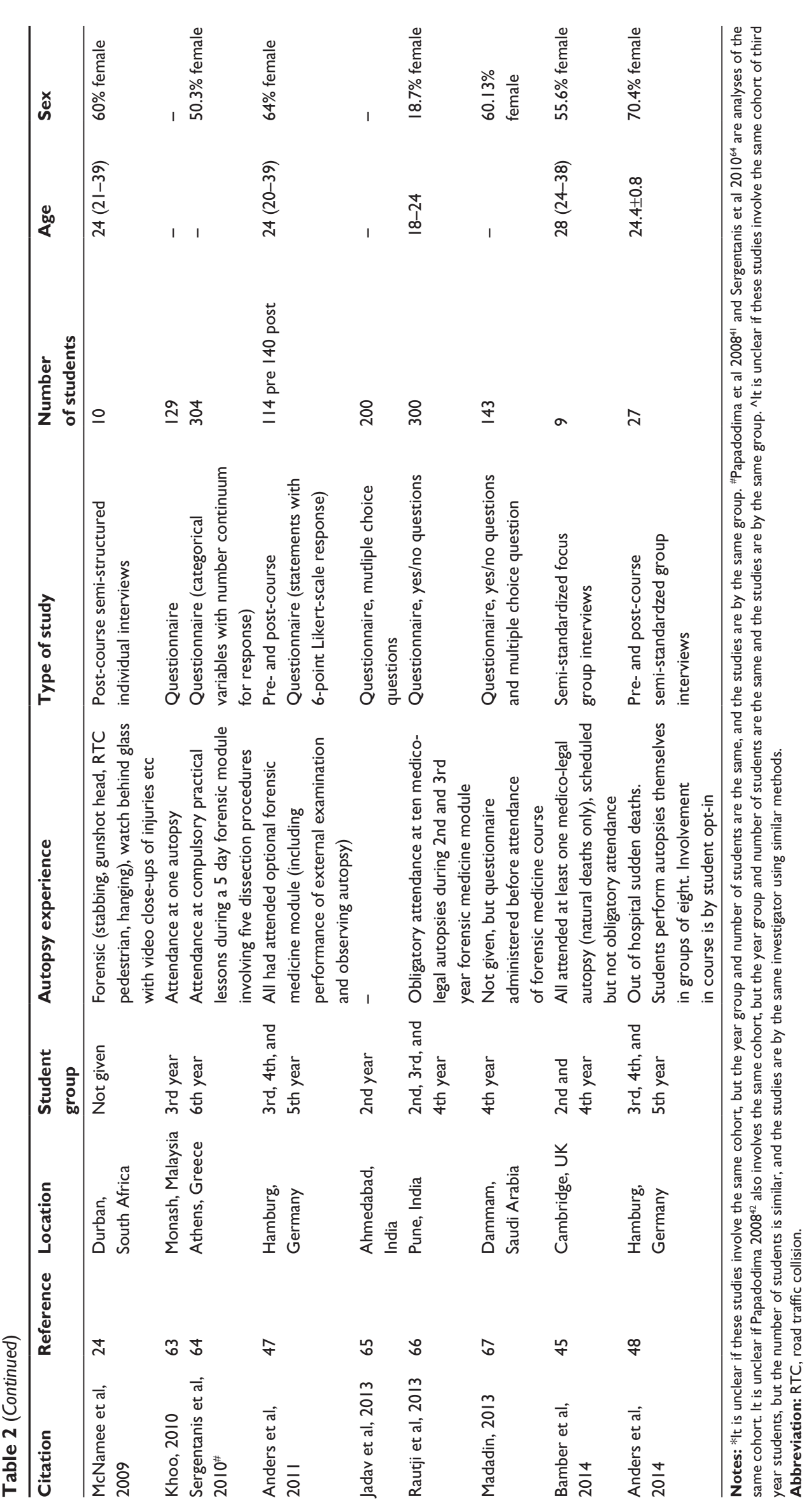


Table 3 Common themes arising from studies of medical student attitudes to the use of the autopsy in medical education

\begin{tabular}{lll}
\hline Theme & References supporting & References refuting \\
\hline Cognitive & & \\
Useful tool in medical education & $24,41,45,46,47,51,55,58,59,61,63,65$ & 60 \\
Improved understanding of clinical sciences (eg, anatomy) & $24,42,45,46,48,51,52,62$ & - \\
Useful for quality control in medical practice, clinical correlation, & $24,45,46,51,52,59$ & 60 \\
understanding of the fallibility of medicine & & - \\
Improves problem-based thinking & $24,45,51$ & 24,45 \\
Attendance should be compulsory & 46,63 & - \\
Repeated attendance is useful & $24,45,61,62,65$ & - \\
Adequate preparation and review is important & $24,45,47,49$ & - \\
Behavior and quality of instructor and mortuary staff important/hidden curriculum & $24,45,46,47,59,62$ & \\
Emotional & & 5 I \\
Allows students to establish empathy/respect/compassion & $24,41,46,57$ & 5 I \\
Improved understanding of death/allows for reflection on mortality & $24,46,47,48$ & - \\
Felt better about approaching relatives regarding autopsy & $45,48,51,57$ & $24,45,55,57,58$ \\
Would be happy with their own autopsy/those on relatives/those on known individuals & - & - \\
Psychological improvement with repeated attendance & $45,52,57,58$ & - \\
Students raise concern regarding psychological risk/discomfort & $24,42,45,48,64$ & \\
Societal & & 60 \\
Useful for society/public/medicine in general terms & $45,55,57,58,59,63$ & \\
\hline
\end{tabular}

learning about the fallibility of medicine. In several studies the behavior and attitudes of instructors and mortuary staff was found to be a key factor in the benefits students derived from attendance.

Many studies discuss the potential negative psychological effects of attendance, some of which appear to apply to specific demographic groups (eg, women). ${ }^{64}$ However some studies also note that such effects could be ameliorated by appropriate preparation and behavior by the instructor. General concern regarding attendance at autopsies of individuals personally known to the students (eg, family members) has been highlighted. ${ }^{45}$ Students' opinions about attending autopsies of patients in whose care they had been involved have been found to be divided. Some studies have reported reluctance, while others highlight the perceived utility of the autopsy as a tool for review of clinical practice and clinic-pathological correlation. However the unpleasant physical esthetic of the mortuary and autopsy was highlighted in practically every study, although often only a significant problem for a small number of students. Repeated attendance was recommended by students in a number of studies as a remedy for the unpleasant psychological effects and the shock of first time attendance.

Whilst students appear generally in favor of attendance, marked disagreement as to whether attendance should be compulsory has been found. In some studies students strongly supported compulsory attendance, and in others this was strongly rejected. This discrepancy may reflect differing styles of autopsy attendance and teaching undertaken by the students.
In common with the opinions of educators, students have also been found to place particular emphasis on the benefit of autopsy attendance with regard to the "hidden curriculum" in medical education. ${ }^{24,45,47,53}$

\section{Conclusion}

The current status of postmortem teaching in the UK as established by the small survey conducted as part of this review, appears to be that of a teaching resource in decline. It has become uncommon for medical students to attend more than a handful of autopsies during their training, and some may never see an autopsy. This flies in the face of opinions of faculty and students, both in this survey and in the published literature, that postmortems are an immensely useful tool for teaching a variety of disciplines; particularly with regard to clinical sciences, medical fallibility, end of life issues, audit, and the "hidden curriculum". This decline in the use of autopsy for teaching, is at least in part, a consequence of the decreasing autopsy rate in the UK and elsewhere, and of a lack of clarity over which cases are appropriate for medical student teaching in the UK. However, increasing demands on the time of students and teachers also play a significant role, and the degree to which autopsies are used for teaching appears variable, and dependent on the presence of a histopathologist with a particular interest in driving forward autopsy-based teaching. Despite a number of papers in the literature discussing alternative methods of teaching using autopsies or autopsy-derived principles, the use of such alternatives does not appear to be widespread, although their use appears to be increasing. 
The richness of the autopsy in terms of the benefits for students as perceived by both faculty, and by students themselves, should be highlighted to medical schools and attendance of autopsies, or the development of alternative teaching methods utilizing autopsy principles, actively encouraged. The difficulties of time management that such approaches raise could be addressed by the more widespread involvement of anatomical pathology technologists and trainee histopathologists. More autopsies might be available for medical student teaching if national consensus was reached regarding appropriate attendance of medical students at coronial autopsies.

Where medical schools actively use autopsies in teaching, it should be recognized that maximum educational benefit can only be achieved when teaching is structured, with clear outcomes, and delivered by an inspiring instructor who behaves appropriately, and when students are adequately prepared for the practical esthetic of the mortuary and autopsy, and given the opportunity to attend on multiple occasions.

\section{Disclosure}

The authors have no conflicts of interest to disclose.

\section{References}

1. Rothenberg, K. The Autopsy Through History. In: Embar-seddon A, Pass AD, editors. Forensic Science. Ipswich MA: Salem Press; 2008:100.

2. Goldman L, Sayson R, Robbins S, Cohn LH, Bettmann M, Weisberg M. The value of the autopsy in three medical eras. $N$ Engl $J$ Med. 1983;308(17):1000-1005.

3. Peacock SJ, Machin D, Duboulay CE, Kirkham N. The autopsy: A useful tool or an old relic? J Pathol. 1988;156(1):9-14.

4. Galloway M. The role of the autopsy in medical education. Hosp Med. 1999;60:756-758.

5. Shojania KG, Burton EC, McDonald KM, Goldman L. Changes in rates of autopsy-detected diagnostic errors over time: a systematic review. JAMA. 2003;289(21):2849-2856.

6. O'Grady G. Death of the teaching autopsy. BMJ. 2003;327(418): 802-803.

7. Gillingwater TH. The importance of exposure to human material in anatomical education: A philosophical perspective. Anat Sci Educ. 2008;1(6):264-266.

8. Horowitz RE, Naritoku WY. The autopsy as a performance measure and teaching tool. Hum Pathol. 2007;38(5):688-695.

9. Talmon G. The use of autopsy in preclinical medical education: A survey of pathology educators. Arch Pathol Lab Med. 2010;134(7): 1047-1053.

10. Benbow EW. Why show autopsies to medical students? J Pathol. 1990;162(3):187-188.

11. Marshall R, Cartwright N, Mattick K. Teaching and learning pathology: A critical review of the English literature. Med Educ. 2004;38(3): 302-313.

12. Hill RB, Anderson RE. The uses and value of the autopsy in medical education as seen by pathology educators. Acad Med. 1991;66(2): 97-100.

13. Burton JL. The autopsy in modern undergraduate medical education: A qualitative study of uses and curriculum considerations. Med Educ. 2003;37(12):1073-1081.
14. Police and Criminal Evidence Act 1984, London: Stationery Office; 1984 c60.

15. Loughrey MB, McCluggage WG, Toner PG. The declining autopsy rate and clinicians' attitudes. Ulster Med J. 2000;69(2):83-89.

16. Burton JL. A bite into the history of the autopsy: from ancient roots to modern decay. Forensic Sci Med Pathol. 2005;1:277-284.

17. Shojania KG, Burton EC. The vanishing nonforensic autopsy. $N$ Engl J Med. 2008;358(9):873-875.

18. Burton JL, Wells M. The Alder Hey affair: Implications for pathology practice. J Clin Pathol. 2001;54(11):820-823.

19. Domizio P, Wilkinson M. Pathology teaching in the twenty-first century. Clin Teach. 2006;3:53-59.

20. The Royal College of Pathologists. Curriculum for specialty training in histopathology. Royal College Of Pathologists; 2010. Available from: http://www.rcpath.org/Resources/RCPath/Migrated\%20Resources/ Documents/H/histopathology_curriculum_ar.pdf. Accessed October 10, 2014.

21. Parham DM. The hidden increase in histopathologists' workload. J Clin Pathol. 1996;49(8):689-690.

22. Morrow W. Backlog: The new phenomenon in histopathology. Biomed Sci. 2010;54:418-419.

23. Beh PS. Death of the teaching autopsy: In Hong Kong teaching autopsies have been championed in public mortuaries. BMJ. 2004; 328(7432): 166.

24. McNamee LS, O'Brien FY, Botha JH. Student perceptions of medicolegal autopsy demonstrations in a student-centered curriculum. Med Educ. 2009;43(1):66-73.

25. The Coroners (Investigations) Regulations 2013, London: Stationery Office; 2013 No1629, Part 3, Regulation 13(5)(a).

26. O'Grady G. The breakfast club: Case study of a teaching-autopsy curriculum. Med Teach. 2004;26(4):377-378.

27. Roberts LW, Nolte KB, Warner TD, McCarty T, Rosenbaum LS, Zumwalt R. Perceptions of the ethical acceptability of using medical examiner autopsies for research and education: A survey of forensic pathologists. Arch Pathol Lab Med. 2000;124(10):1485-1495.

28. Burton JL. Getting consent for necropsies: Perhaps we should seek consent to show necropsies to students. BMJ. 2001;323(7326):1426.

29. Sayers GM, Mair J. Getting consent for autopsies: Who should ask what and why? BMJ. 2001;323:521.

30. McDermott MB. Obtaining consent for autopsy. BMJ. 2003; 327(7418):804-806.

31. Rose S. Death of the teaching autopsy: Histopathologists should not obtain consent for autopsy. BMJ. 2004;328(7432):166.

32. Coroners and Justice Act 2009, London: Stationery Office; 2009 c25.

33. Nash JR. Pathology in the new medical curriculum: What has replaced the subject courses? Pathol Oncol Res. 2000;6(2):149-154.

34. Heylings DJ. Anatomy 1999-2000: The curriculum, who teaches it and how? Med Educ. 2002;36(8):702-710.

35. McHanwell S, Atkinson M, Davies DC, et al. A core syllabus in anatomy - Adding common sense to need to know. Eur J Anat. 2007;11:S3-S18.

36. Bergman EM, Prince KJ, Drukker J, van der Vleuten CP, Scherpbier AJ. How much anatomy is enough? Anat Sci Educ. 2008;1(4): 184-188.

37. Drake RL, McBride JM, Lachman N, Pawlina W. Medical education in the anatomical sciences: The winds of change continue to blow. Anat Sci Educ. 2009;2(6):253-259.

38. Sugand K, Abrahams P, Khurana A. The anatomy of anatomy: A review for its modernization. Anat Sci Educ. 2010;3(2):83-93.

39. Johnson EO, Charchanti AV, Troupis TG. Modernization of an anatomy class: From conceptualization to implementation. A case for integrated multimodal-multidisciplinary teaching. Anat Sci Educ. 2012;5(6): 354-366.

40. Hisley KC, Anderson LC, Smith SE, Kavic SM, Tracy JK. Coupled physical and digital cadaver dissection followed by a visual test protocol provides insights into the nature of anatomical knowledge and its evaluation. Anat Sci Educ. 2008;1(1):27-40. 
41. Papadodima SA, Sergentanis TN, Iliakis RG, Sotiropoulos KC, Spiliopoulou CA. Students who wish to specialize in forensic medicine vs their fellow students: motivations, attitudes and reactions during autopsy practice. Adv Health Sci Educ Theory Prac. 2008;13(4): 535-546.

42. Papadodima SA, Sergentanis TN, Iliakis RG, Sotiropoulos KC, Spiliopoulou CA. In the university morgue: medical students' physical symptoms, perceptions, concerns and feelings before and after the forensic practical course. Med Teach. 2008;30:103-105.

43. Boeckers A, Brinkmann A, Jerg-Bretzke L, Lamp C, Traue HC, Boeckers TM. How can we deal with mental distress in the dissection room? An evaluation of the need for psychological support. Ann Anat. 2010;192(6):366-372.

44. Tam MD. Building virtual models by postprocessing radiology images: A guide for anatomy faculty. Anat Sci Educ. 2010;3(5):261-266.

45. Bamber AR, Quince TA, Barclay SIG, Clark JDA, Siklos PWL, Wood DF. Medical student attitudes to the autopsy and its utility in medical education: a brief qualitative study at one UK medical school. Anat Sci Educ. 2014;7(2):87-96.

46. Conran P, Nowacek G, Adams T, Smith L. Medical students' attitudes toward the autopsy. Acad Med. 1996;71(6):681-683.

47. Anders S, Fischer-Bruegge D, Fabian M, Raupach T, Petersen-Ewert C, Harendza S. Teaching post-mortem external examination in undergraduate medical education - The formal and the informal curriculum. Forensic Sci Int. 2011;210(1-3):87-90.

48. Anders S, Mueller M, Sperhake JP, Petersen-Ewert C, Schiekirka S, Raupach T. Autopsy in Undergraduate Medical Education - what do students really learn? Int J Legal Med. 2014;128(6):1031-1038.

49. de Villiers FP, Ruhaya M. Students' opinions on autopsy and death. S Afr Fam Pract. 2005;47(1):47-50.

50. Hunt NC, James DS, Bull AD. The still video camera: a suitable and convenient method of demonstrating post mortem findings. Med Educ. 1997;31(5):386-389.

51. DeRoy AK. The autopsy as a teaching-learning tool for medical undergraduates. J Med Educ. 1976;51(12):1016-1018.

52. Tazelaar HD, Schneiderman H, Yaremko L, Weinstein RS. Medical students' attitudes toward the autopsy as an educational tool. J Med Educ. 1987;62(1):66-68.

53. Benbow EW. Medical students' views on necropsies. J Clin Pathol. 1990;43(12):969-976.

54. Benbow EW. How do we teach pathology? Autopsy demonstrations to medical students: Audit by questionnaire. J Pathol. 1990;162(2): $177-179$.
55. Sanner MA. Medical students' attitudes toward autopsy. How does experience with autopsies influence opinion? Arch Pathol Lab Med. 1995;119(9):851-858.

56. Salacin S, Çekin N, Özdemir MH, Kalkan S. A questionnaire survey applied to undergraduate students who have taken the course on Forensic Medicine. Bull Legal Med. 1997;1/2:21-24.

57. Botega NJ, Metze K, Marques E, et al. Attitudes of medical students to necropsy. J Clin Pathol. 1997;50(1):64-66.

58. Verma SK. Teaching students the value of autopsies. Acad Med. 1999;74(8):855.

59. Inanici MA, Sozen MS, Alkan N, Arican N, Aksoy ME. The attitudes of medical students to autopsy. Forensic Sci Int. 2000;113(1-3): 303-308.

60. Ruhaya M, de Villiers FP. Medical students' experiences of the autopsy. S Afr Med J. 2003;93(4):281-283.

61. Ekanem VJ, Akhigbe KO. Attitudes of Nigerian medical students towards autopsy. Turk J Med Sci. 2006;36:51-56.

62. Kucuker H, Ozen OA, Songur A, Bas O, Demirel R. Should forensic autopsies be a source for medical education? A preliminary study. Teach Learn Med. 2008;20(1):22-25.

63. Khoo JJ. Third-year medical students' views on autopsies. Pathology. 2010;42(Suppl 1):S71.

64. Sergentanis TN, Papadodima SA, Evaggelakos CI, Mytilinaios DG, Goutas ND, Spiliopoulou CA. Students' physical and psychological reactions to forensic dissection: Are there risk factors? Anat Sci Educ. 2010;3(6):287-294.

65. Jadav JC, Patel BN, Shah KA, Tandon RN. Knowledge and attitude of medical students on forensic autopsy in Ahmedabad city. J Indian Acad Forensic Med. 2013;35(1):26-28.

66. Rautji R, Kumar A, Behera C. Attitudes of medical students towards medico-legal/clinical autopsy. J Indian Acad Forensic Med. 2013 35(4):358-361.

67. Madadin MS. Assessment of knowledge about, attitudes toward, and awareness of a forensic medicine course among medical students at the University of Dammam. J Forensic Leg Med. 2013;20(8): 1108-1111.

68. Illeris K. Towards a contemporary and comprehensive theory of learning. Int J Lifelong Educ. 2003;22:396-406.

69. Illeris K. The Three Dimensions of Learning. 2nd ed. Gylling Denmark: Narayana Press; 2004 


\section{Supplementary material}

\section{Medical student attendance at post mortem examinations}

Medical School:

1. Do your undergraduate medical students attend post mortem examinations?

$\square$ Yes - Go to question 2

No - Go to question 9

2. Is such attendance optional or compulsory?

$\square$ Optional $\quad-$ Go to question 3

Compulsory - Go to question 4

3. Is attendance encouraged at all? If it is, how is this achieved?

4. At what stage does attendance take place?

5. Is attendance integrated into the course?

6. Are attendances structured in any way (eg, structured questions, reflective writings etc)?

7. What format does the session take (eg, observing the whole autopsy, or seeing eviscerated individual organs)?

8. How many post mortem examinations on average would your students attend?

Please go to question 12

9. Could they attend post mortem examinations if they wished?

$\square$ Yes - Go to question 11

$\square$ No - Go to question 10

10. Please could you explain briefly why not?

Please go to question 12

11. Please explain very briefly how they would have to make arrangements to do so.

12. Are the principles of the autopsy used in ways other than direct observation at your institution (eg, virtual autopsies, online modules, case studies etc)?

13. Do you think attending post mortems had educational benefits for medical students? If so, what are they?

14. Please list below any further comments regarding the use of the autopsy for medical education in your institution and in general which you feel may be of interest to the study team.

Many thanks for taking the time to complete this questionnaire. Should you wish to be apprised of the findings of the study, please write a contact email address below:

Advances in Medical Education and Practice

Dovepress

\section{Publish your work in this journal}

Advances in Medical Education and Practice is an international, peerreviewed, open access journal that aims to present and publish research on Medical Education covering medical, dental, nursing and allied health care professional education. The journal covers undergraduate education, postgraduate training and continuing medical education

including emerging trends and innovative models linking education, research, and health care services. The manuscript management system is completely online and includes a very quick and fair peer-review system. Visit http://www.dovepress.com/testimonials.php to read real quotes from published authors.

Submit your manuscript here: http://www.dovepress.com/advances-in-medical-education-and-practice-journal 